\title{
Postmortem study of ataxia with retinitis pigmentosa by mutation of the $\alpha$-tocopherol transfer protein gene
}

T Yokota, T Uchihara, J Kumagai, T Shiojiri, J J Pang, M Arita, H Arai, M Hayashi, M Kiyosawa, R Okeda, H Mizusawa
Department of

Neurology, Tokyo

Medical and Dental

University, 1-5-45

Yushima, Bunkyo-ku,

Tokyo 113-8519, Japan

T Yokota

T Uchihara

T Shiojiri

H Mizusawa

Department of

Pathology

J Kumagai

Department of Neuropathology,

Medical Research

Institute

R Okeda

Department of

Ophthalmology

J J Pang

M Kiyosawa

Department of Health Chemistry, Faculty of Pharmaceutical

Sciences, University of Tokyo, 7-3-1 Hongo,

Bunkyo-ku, Tokyo 113,

Japan

M Arita

H Arai

Department of

Neuropathology, Tokyo

Metropolitan Institute

for Neuroscience,

2-6-1 Musashidai

Fuchu-shi, Tokyo 183,

Japan

T Uchihara

Department of

Neurology, Tokyo

Metropolitan

Neurological Hospital,

2-6-1 Musashidai

Fuchu-shi, Tokyo 183,

Japan

M Hayashi

Correspondence to:

Dr T Yokota

tyokota@ buckcenter.org

Received 17 February 1998 and in revised form

19 October 1999

Accepted 29 October 1999

\begin{abstract}
A new syndrome of ataxia and retinitis pigmentosa with vitamin $E$ deficiency caused by the missense mutation of $\alpha$-tocopherol transfer protein ( $\alpha$-TTP) gene was recently proposed. After studying the first postmortem case with this mutation pathologically and biochemically, whether the symptoms can be treated by supplementation of vitamin $E$ or not is discussed. The major pathological findings were retinal atrophy; severe dying back-type degeneration of the posterior column; and massive accumulation of lipofuscin in neurons including dorsal root ganglion (DRG) cells, which were almost identical to those in vitamin $E$ deficient animals and patients with fat malabsorption. Also, mild loss of Purkinje cells was noted. Because robust expression of $\alpha$-TTP was detected in the cerebellum as well as in the liver and the tissue concentration of vitamin $E$ in the cerebellum was still low even after oral supplementation, the mild Purkinje cell loss might be related to the mutant $\alpha$-TTP in the cerebellum. By contrast, in the DRG, thought to be mainly responsible for ataxia, no expression of $\alpha$-TTP was detected, and the tissue concentration of vitamin $E$ increased to normal after supplementation. It is therefore considered that oral supplementation of vitamin E should effectively counteract the progression of ataxia.

(F Neurol Neurosurg Psychiatry 2000;68:521-525)
\end{abstract}

Keywords: ataxia; retinitis pigmentosa; $\alpha$-tocopherol transfer protein; vitamin $\mathrm{E}$

Vitamin E is the most potent lipid soluble antioxidant in biological membranes where it contributes to membrane stability. The four major natural isomers of vitamin $\mathrm{E}(\alpha-, \beta-, \gamma-$, and $\alpha$-tocopherol) are absorbed from the small intestine and transported in chylomicrons to the liver. There, $\alpha$-tocopherol is incorporated into nascent very low density lipoproteins, which then enter circulation. The $\alpha$-tocopherol transfer protein ( $\alpha$-TTP) is presumed to func- tion in this transfer of $\alpha$-tocopherol in the liver. We previously reported adult onset cases with mild progressive ataxia syndrome in which there was isolated vitamin $\mathrm{E}$ deficiency. ${ }^{1}$ We isolated the $\alpha$-TTP complementary $\mathrm{DNA}^{2}$ and found that mutations of the $\alpha$-TTP gene cause ataxia with isolated vitamin $\mathrm{E}$ deficiency. ${ }^{34}$ Furthermore, we clarified that a missense mutation at codon 101 of the $\alpha$-TTP gene may cause retinitis pigmentosa as well. ${ }^{5}{ }^{6}$ Here, we report the first necropsy findings for a patient with this mutation and discuss the rationale and the limitation of the supplement therapy.

\section{Patient and methods}

CASE REPORT

The proband was a 73 year old man who had been healthy until the age of 52 when he became aware of gait unsteadiness in the dark. At the age of 56, he experienced night blindness and difficulty in speaking. His gait and visual disturbances progressed slowly until supplement therapy was started at the age of 62.

Neurologically, there was mild dysarthria and moderate ataxia in the limbs. Knee and ankle jerks were absent and plantar responses were flexor. Joint position sense was lost in the toes, and vibration sense was markedly reduced below the elbows and iliac crests. Gait was broad based and ataxic, and Romberg's sign was positive. Ophthalmologically, he had reduced visual acuity (0.6/0.6) with partially impaired dark adaptation. His fundus was tigroid, and paramacular granular hyperfluorescence was found on fluorescein angiography. Goldman's perimetry showed ring scotoma. Electroretinographic examination showed reduced $\mathrm{a}$ and $\mathrm{b}$ waves in both eyes as well as a reduction of oscillatory potentials. These findings are compatible with retinitis pigmentosa sine pigment.

The family members examined were normal, except for the proband's uncle who showed absent knee and ankle jerks and decreased joint position senses below the knees. Vitamin E concentrations were low in the proband (2.1 $\mu \mathrm{g} / \mathrm{ml}$; normal, 5-15) and the uncle (3.2 $\mu \mathrm{g} / \mathrm{ml})$. 


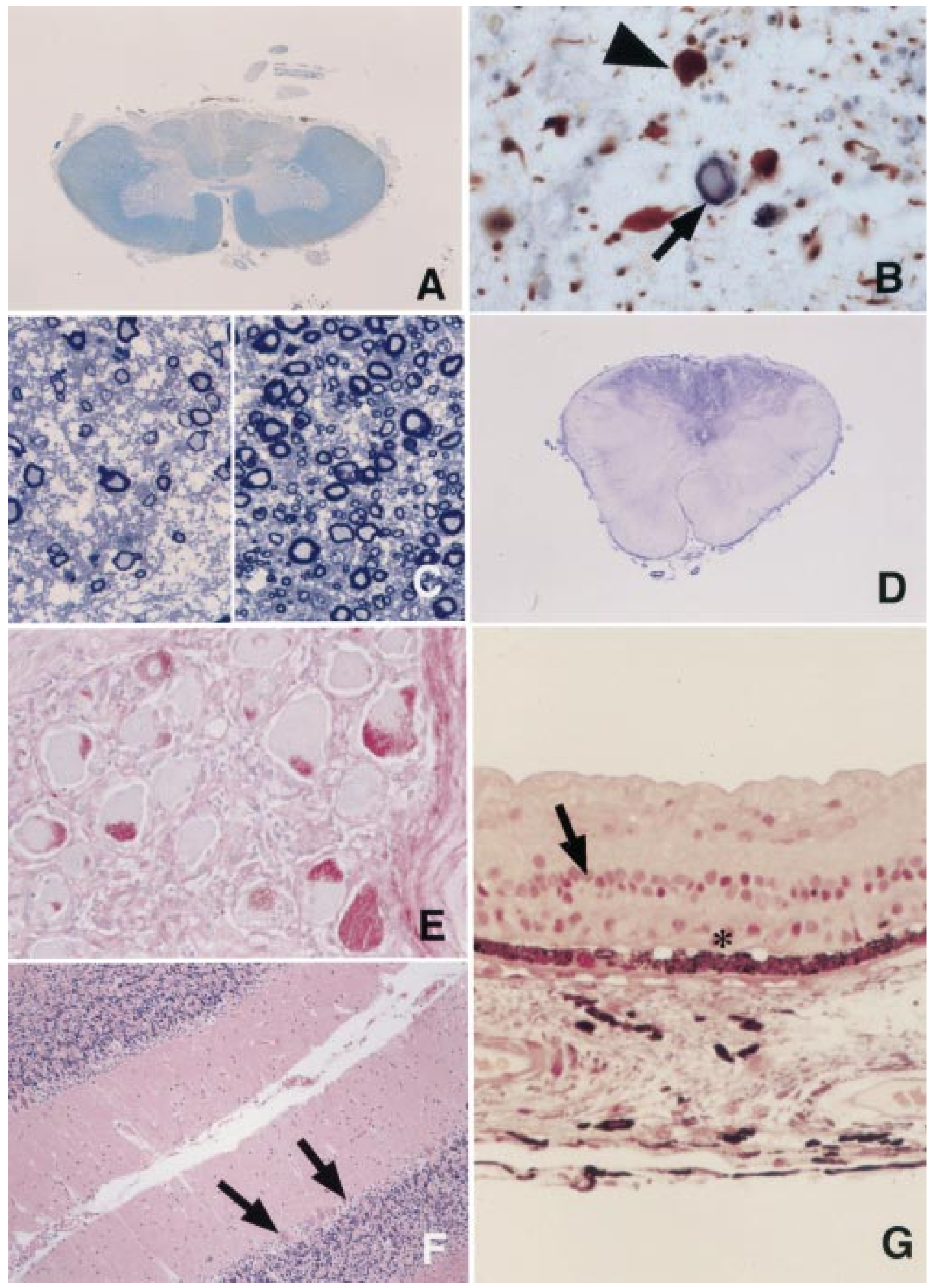


Results of brain MRI and single photon emission computed tomography (SPECT) were normal. Somatosensory evoked potential, and visually evoked potential were abnormal. ${ }^{6}$ The proband was homozygous and his children heterozygous for the point mutation that replaces histidine (CAT) with glutamine (CAG) at position 101 of the $\alpha$-TTP gene. ${ }^{4} 6$

Oral administration of all-rac- $\alpha$-tocopheryl acetate (300 IU/day), resulted in an increase in serum vitamin $\mathrm{E}$ concentration to normal $(15.5 \mu \mathrm{g} / \mathrm{ml})$, Romberg's sign became negative 7 months after administration, and there was no worsening of visual and neurological symptoms over the 11 years until his death. He died of pancreatic cancer at the age of 73 .

\section{PATHOLOGICAL ANALYSIS}

Tissues were fixed with formalin, embedded in paraffin, and stained by conventional methods. In addition, transverse sections ( $2 \mathrm{~mm}$ thick) of a unilateral half of the spinal cord were fixed for 2 days in $2.5 \%$ glutaraldehyde buffered by $0.1 \mathrm{M}$ phosphate then washed with $0.01 \mathrm{M}$ phosphate buffered saline. After osmification with osmium tetroxide for 6 hours, they were dehydrated with graded alcohol, transferred to propyleneoxide, and embedded in Epon 812. Sections of $1 \mu \mathrm{m}$ were obtained and stained by toluidine blue.

For immunohistochemistry for the detection of spheroid and corpora amylacea, sections were treated with $0.5 \%$ hydrogen peroxide for 30 minutes and were then incubated with the antineurofilament antibody, SMI31(SternbergerMeyer). Immnolabelling was visualised by the avidin-biotin peroxidase method (ABC-Elite, Vector) with diaminobenzidine (DAB) and nickel sulphate as chromogen. For double labelling immunohistochemistry, sections which had been subjected to the purple $\mathrm{DAB}$ reaction were treated with $0.5 \%$ hydrogen peroxide before the second cycle with antiubiquitin antibody $(1: 2000, \mathrm{DAKO})$ as a primary antibody. The subsequent procedure was the same as for the first cycle, except that the second DAB reaction was carried out in the absence of nickel ammonium sulphate to yield a brown reaction product.

\section{NORTHERN BLOT ANALYSIS}

The membranes were loaded with $2 \mu \mathrm{g}$ each of poly(A)+ RNAs from several human brain tissues (Clontech) and with $10 \mu \mathrm{g}$ total RNAs from the dorsal root ganglia (DRG) and liver, obtained from a necropsy patient who died of cerebral infarction. The method of northern blot was the same as our previous report. ${ }^{6}$

BIOCHEMICAL ANALYSIS OF THE TISSUES

From the patient as well as seven normal controls who had no neurological disease with normal concentration of serum $\alpha$-tocopherol, liver, DRG (L4), cerebral cortex (frontal lobe), and cerebellum (hemisphere) were taken, rapidly frozen, and stored at $-80^{\circ} \mathrm{C}$. The mean (range) of the age of the controls was 68 (59-81) years and that of sampling delay was 7.4 (2-14) hours. Effects of postmortem sampling delay, within 38 hours, on the $\alpha$-tocopherol concentration in the brain is reported to be minimal. ${ }^{7}$ The tissue concentration of $\alpha$-tocopherol was determined by the method reported by Abe and Matsumoto. ${ }^{8}$

\section{Results}

NECROPSY FINDINGS

The necropsy was performed 2 hours 40 minutes postmortem. The brain weighed $1290 \mathrm{~g}$. The brainstem and spinal cord were markedly atrophic with brown coloration of the grey matter.

The major lesion was posterior column degeneration of the dying back type which consisted of marked myelin pallor (figure A), astrocytic proliferation, numerous corpora amylacea and axonal spheroids (figure B), and hyalinisation and thickening of the vascular walls. These changes were more marked in the upper than the lower segments of the spinal cord (figure C) and more severe in the gracile than cuneate fasciculi. The gracile and cuneate nuclei were also severely affected (figure D), showing pyknotic neurons and ghost cells. Posterior roots were also affected less severely than posterior column. By contrast, the DRG cells were well preserved (figure E). In the sural nerve, the morphology and density (8926/ $\mathrm{mm}^{2}$ ) of the myelinated axons were within the normal range. Ventral roots also had normal morphology and density $\left(6805 / \mathrm{mm}^{2}\right.$ in L3) of the myelinated axons.

In the cerebellum, there was slight to moderate focal loss of Purkinje cells (figure F), partially replaced by Bergmann's glia involving both the vermis and hemispheres. The cerebral cortex was normal. The lamination of the lateral geniculate body was obscured because of the pallor of the intervening myelin layers. There was no clear loss of neurons in Clark's nucleus and the dentate nucleus. In the retina, the outer segment of photoreceptor cells was shortened, and the inner layer of the retina was thin and atrophic. In the area where the ring scotoma was present, the outer segment disappeared (figure $\mathrm{G}$ ).

Accumulation of ceroid lipofuscin was conspicuous in the DRG, retinal pigment epithelial, and spinal anterior horn cells, but it was not clear whether it was excessive for a 73 year old man.

TISSUE DISTRIBUTION OF HUMAN A-TTP

Northern blot analysis showed that $\alpha$-TTP was expressed in the cerebral cortex, cerebellum,

Figure: (A) The lower cervical cord (C6) is atrophic, and the myelin of the posterior column shows marked pallor (Klüver-Barrera stain originally $\times 6.0$ ). (B) Numerous axonal spheroids immunostained by antineurofilament antibody, SMI-31 (brown, arrow head) and corpora amylacea by antibiquitin antibody (purple, arrow) in the posterior column nucleus (originall $\times 514$ ). (C) The gracile fasciculi of the upper cervical cord (C3, left) and lower lumbar cord (L2, right) (toluidine blue stain $\times 514$ ), show decreased axon density and thin myelin. These changes are more marked in C3 than those in L2. (D) Lower medulla (Holzer stain originally $\times 4.4$ ). Marked gliosis is present in the gracile and cuneate nuclei. (E) The dorsal root ganglion of right C7 (periodic acid-Shiff originally $\times 210$ ). Ganglion cells are well preserved and Nageotte's nodules are very rare. (F) Cerebellar hemisphere (haematoxylin and eosin originally $\times 64)$. There is focal loss of Purkinje cells. Purkinje cells have almost disappeared in the upper folium, but are relatively preserved in the lower folium (arrow). (G) Retina (haematoxylin and eosin originally $\times 257$ ). The outer segment layer of photoreceptor cells has disappeared (asterisk) and the outer nuclear layer is not obvious. The inner layers of the retina are thin and atrophic (arrow). 
Tissue concentration of a-tocopherol $(\mu \mathrm{g} / \mathrm{g})$

\begin{tabular}{lll}
\hline & Patient & $\begin{array}{l}\text { Normal range (mean) } \\
(n=7)\end{array}$ \\
\hline Liver & 18.2 & $13.0-70.5(21.5)$ \\
DRG & 122.7 & $34.1-101.7(60.4)$ \\
Cerebral cortex & 15.5 & $12.2-31.9(21.5)$ \\
Cerebellum & 4.8 & $10.4-17.7(14.2)$ \\
\hline
\end{tabular}

DRG=Dorsal root ganglion.

and spinal cord, but not in the dorsal root ganglia. The expression level was much higher in the liver than in the brain tissues, and was relatively high in the cerebellum compared with the cerebral cortex and spinal cord.

BIOCHEMICAL ANALYSIS OF THE TISSUE

CONCENTRATION OF VITAMIN E

Concentrations of $\alpha$-tocopherol were in the normal range for liver and cerebral cortex, and higher than normal for DRG, but the concentration was lower than the normal limit for the cerebellum (table).

\section{Discussion}

This is the second necropsy report of ataxia with isolated vitamin $\mathrm{E}$ deficiency due to mutation of the $\alpha$-TTP gene and follows the report of a Tunisian patient with a $744 \mathrm{del} A$ frame shift mutation. ${ }^{9}$ The phenotype and deficiency of serum vitamin $\mathrm{E}$ are known to be more severe in 744delA than in His $101 \mathrm{Gln}$ patients, but the symptoms basically are similar in those with both mutations except for visual problems. ${ }^{6}$ The cardinal neuropathological changes, the marked dying back-type degeneration of the posterior column with numerous corpora amylacea and spheroids, massive ceroid lipofuscin accumulation in the cells including DRG cells, and mild loss of Purkinje cells, were present in both patients. These findings, except the loss of Purkinje cells, are very similar to those seen in vitamin $\mathrm{E}$ deficient monkeys, rats, and horses ${ }^{10}$ and in human patients with secondary vitamin E deficiency. ${ }^{12}$ Dying back degeneration of the central axon of the DRG cell with a relatively preserved peripheral axon is a characteristic finding in vitamin $\mathrm{E}$ deficient animals. ${ }^{11}$ The more extensive distribution of ceroid lipofuscin deposits was seen in the Tunisian patient with a frameshift mutation ${ }^{9}$ than in our patient with a missense mutation. This is probably due to the difference in the severity of the deficiency of serum vitamin $\mathrm{E}$. These neuropathological findings due to $\alpha$-TTP gene mutation are clearly different from Freidreich's ataxia in that they lack primary and severe loss of DRG cells and Clarke's nucleus, and dentate nucleus, although neurological symptoms are similar to each other.

The tissue concentration of $\alpha$-tocopherol remained low in the cerebellum, even after $\alpha$-tocopherol supplementation, but normal or higher than normal in the liver, DRG, and cerebral cortex. The mechanisms by which $\alpha$-tocopherol enters the nervous system and reaches the neurons in each tissue have not been clarified, but the LDL receptor is reported to deliver $\alpha$-tocopherol to certain cells $^{13}$ and to transfer lipids across the bloodbrain barrier. ${ }^{14}$ We recently showed that the localisation of $\alpha$-TTP is not restricted to the liver but includes the cerebellum and retina. ${ }^{6}{ }^{15}$ Even more interesting, one of the common findings in the two necropsy cases with mutations of the $\alpha$-TTP gene was mild loss of Purkinje cells, a finding not described in reports of vitamin $\mathrm{E}$ deficient animals. ${ }^{10}{ }^{11}$ These findings suggest that $\alpha$-TTP in the cerebellum functions in delivering $\alpha$-tocopherol to the cerebellum, and that its mutation has a role in Purkinje cell loss.

There are two possible lesions responsible for the ataxia in our patient; the posterior column and Purkinje cells. His major features of ataxia: positive Romberg's sign, loss of deep sensation, and areflexia, indicated severe posterior column dysfunction, which was confirmed by electrophysiological investigations. ${ }^{6}$ By contrast, there were no signs indicating vestibulocerebellar dysfunction, such as nystagmus, nor abnormalities in the cerebellum on brain MRI and SPECT. ${ }^{6}$ The ataxia in this patient therefore is considered to be caused mainly, if not exclusively, by a posterior column lesion. Furthermore, $\alpha$-TTP was not expressed in the DRG cell, the parent neuron of the posterior column axon, and oral administration of $\alpha$-tocopherol raised the tissue concentrations in DRG and cerebral cortex to normal. These findings provide a rationale for the use of the oral supplementation of vitamin $\mathrm{E}$ as therapy for the ataxia caused by $\alpha$-TTP gene mutation. This conclusion is supported by our finding that the symptoms were partially ameliorated or did not progress for more than 10 years after supplementation. ${ }^{13}$

This study was supported by grants from the Ministry of Education, Science and Culture, Japan (A-138, 10557064), Japan Health Sciences Foundation, and Ezai Co. We thank Dr Kouichi Abe, Ms Emiko Kawakami, Dr Yuko Seko, and Dr Kazuyuki Ishida for their help.

1 Yokota T, Wada Y, Furukawa T, et al. Adult-onset spinocerbellar syndrome with idiopathic vitamin E deficiency. Ann Neurol 1987;22:84-7

2 Arita M, Sato Y, Miyata A, et al. Human $\alpha$-tocopherol transfer protein: cDNA cloning, expression and chromosomal localization. Biochem f 1995;306:437-43.

3 Ouahchi K, Arita M, Kayden HJ, et al. Ataxia with isolated vitamin $\mathrm{E}$ deficiency is caused by mutations in the $\alpha$-tocopherol transfer protein. Nat Genet 1995;9:141-5.

4 Gotoda T, Arita M, Arai H, et al. Adult-onset spinocerebellar dysfunction caused by a mutation in the gene for the $\alpha$-tocopherol-transfer protein. $N$ Engl f Med 1995;333: 1313-18.

5 Yokota T, Shiojiri T, Gotoda T, et al. Retinitis pigmentosa and ataxia caused by mutation in the $\alpha$-tocopherol transfer protein gene. N Engl f Med 1996;335:1770-1.

protein gene. $N$ Engl $\mathcal{F}$ Med 1996;335:1770-1.
6 Yokota T, Shiojiri T, Gotoda T, et al. Friedreich-like ataxia yith retinitis pigmentosa caused by the His $101 \mathrm{Gln}$ with retinitis pigmentosa caused by the His $101 \mathrm{Gln}$
mutation of $\alpha$-tocopherol transfer protein gene. Ann Neurol

7 Metcalfe T, Bowen DM, Muller DPR. Vitamin E concentration in human brains of patients with Alzheimer's disease, fetuses with Down's syndrome, centenarians, and controls. Neurochem Res 1989;14:1209-12.

8 Abe K, Matsumoto A. Quantitative determination of tocopherols. In: Mino M, Nakamura H, Diplock AT, et al, eds. Vitamin E. Its usefulness in health and curing diseases. Tokyo: Japan Scientific Societies Press, Tokyo, and S Karger AG, Switzerland, 1993:13-19.

9 Larnaout A, Belal S, Zouari M, et al. Friedreich ataxia with isolated vitamin $\mathrm{E}$ deficiency: a neuropathological study of a Tunisian patient. Acta Neuropathol 1997;93:633-7.

10 Nelson JS, Fitche CD, Fische VW, et al. Progressive neuropathologic lesions in vitamin E-deficient rhesus monneuropathologic lesions in vitamin E-deficient r
key. F Neuropathol Exp Neurol 1981;40:166-86.

11 Southam E, Thomas PK, King RHM, et al. Experimental vitamin E deficiency in rats. Brain 1991;114:915-93. 
12 Satya-Murti S, Howard L, Krohel G, et al. The spectrum of neurologic disorders from vitamin E deficiency. Neurology

13 Traber MG, Kayden HJ. Vitamin E is delivered to cells via the high affinity receptor for low-density lipoprotein. $A m \mathcal{F}$ Clin Nutr 1984;40:747-51.
14 Dehouck B, Fenart L, Dehouck M-P, et al. A new function for the LDL receptor: transcytosis of LDL across the

15 Hosomi A, Goto K, Kondo $\mathrm{H}$, et al. Localization of $\alpha$-tocopherol transfer protein in rat. Neurosci Lett 1998;256: $159-62$.

\section{NEUROLOGICAL PICTURE}

\section{Reversal sign after cardiopulmonary arrest}

A 70 year old man with a 20 year history of diabetes mellitus and moderate hypertension was found unconscious in cardiopulmonary arrest of unknown duration. After 10 minutes of unsuccessful cardiopulmonary resuscitation an emergency nasotracheal intubation was performed, and mechanical ventilation was initiated with $100 \%$ oxygen at a rate of 20 per minute. On arrival at the hospital the patient had no detectable pulse and on examination he was unresponsive to noxious stimuli, with the pupils dilated and fixed. All brain stem reflexes were absent. The oxygen tension $\left(\mathrm{PaO}_{2}\right)$ was $58 \mathrm{~mm} \mathrm{Hg}$, the carbon dioxide tension $\left(\mathrm{PaCO}_{2}\right)$ was $54 \mathrm{~mm} \mathrm{Hg}$, and the $\mathrm{pH} 6.77$. He was defibrillated with 200,300 , and $360 \mathrm{~J}$, and therapeutic measures included atropine, adrenalin, dopamine infusion, and lidocaine administration. Resuscitation lasted 1 hour until a recordable blood pressure was obtained. Non-contrast computed tomographic scans of the brain performed 1 hour after resuscitation showed diffuse cerebral oedema with effacement of the cerebral sulci and of the brainstem cisterns. In addition, there was decreased density of grey matter and relative increased density of white matter, a finding referred to as the reversal sign. The middle (curved arrows) and anterior (arrow) cerebral arteries appeared hyperdense due to the absence of intracerebral blood flow (figure A), and the ventricular system was compressed ("slit ventricles" in figure B). These injuries were due to prolonged cardiopulmonary arrest and global brain ischaemia. One hour later cardiopulmonary arrest recurred, and the patient could not be resuscitated. Twenty four hours after admission the patient was declared brain dead and removed from the respirator.

\section{GIUSEPPE BRANCATELLI} ROBERTO LAGALLA

Istituto di Radiologia, 90127 Palermo, Italy

Correspondence to: Dr Giuseppe Brancatelli, The Shadyside Inn, 5405 Fifth Avenue, Pittsburgh, Pa 15232, USA
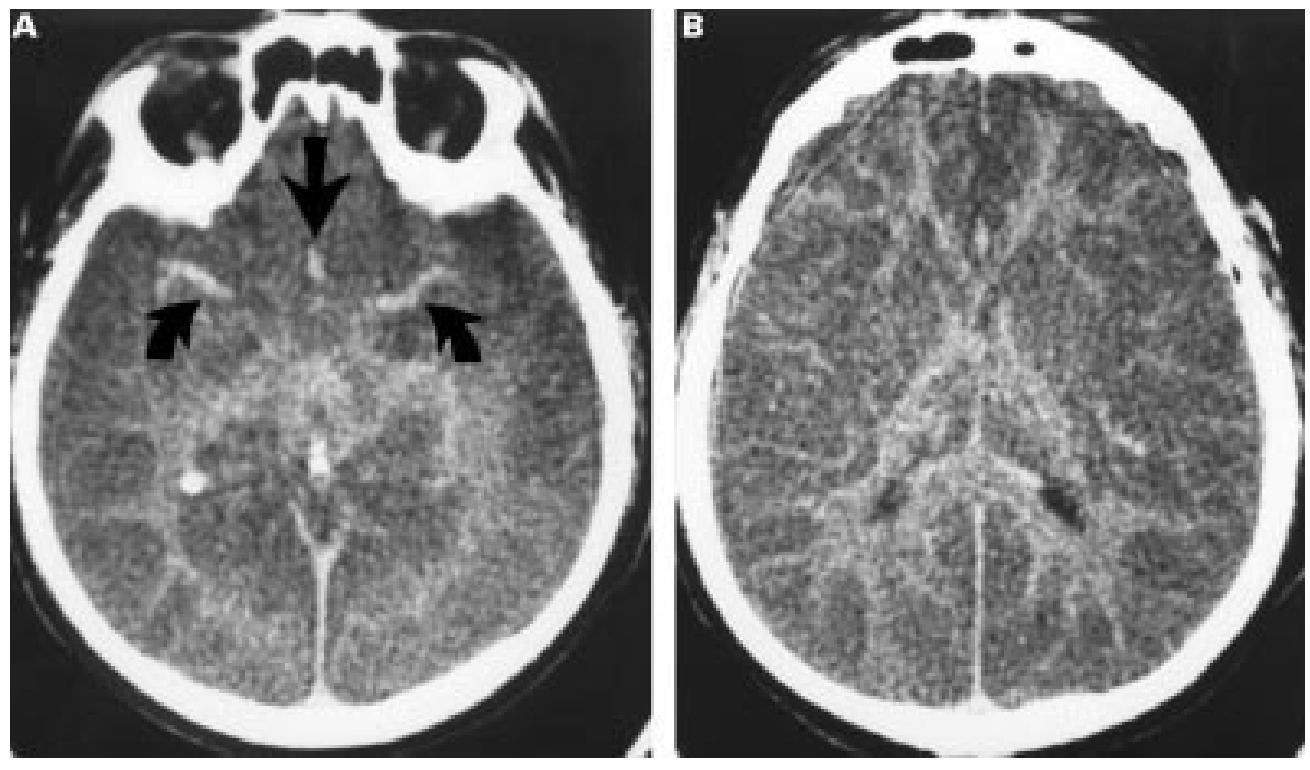